\title{
El Desarrollo humano: Un desafío para las Ciencias Sociales.
}

\section{Conversando con Pedro Güell*}

\section{Presentación}

I a reflexión sobre la sociedad en la que estamos insertos, en el contexto de las profundas y constantes transformaciones de las que somos partícipes, es una actividad que se lleva a cabo periódicamente en el Departamento de Sociología. En estas páginas queremos compartir un encuentro con Pedro Güell, sobre el desafío que representa para las Ciencias Sociales tener como foco de preocupación el desarrollo humano hoy en día. Conversar sobre los resultados del PNUD difundido en el año 2000, no se puede hacer al margen de la experiencia que significa conducir esa secuencia de estudios destinados a evaluar la situación del Desarrollo Humano para Chile; veremos el proceso de construcción y operacionalización de un indicador de desarrollo humano a partir de estadísticas de 176 países.

El concepto de desarrollo humano en su origen, no es un concepto intelectual a pesar de que tiene una potente base intelectual y operacional; es un concepto instrumental que pone sobre el debate principios comunes; es una especie de club exitoso en la incorporación de aliados; lo que queremos compartir es como el club para incorporar aliados termina en un concepto sociológico relativamente potente.

* Coordinador Ejecutivo del Informe de Desarrollo Humano en Chile. Reproducimos en estas líneas la conversación que tuvimos con Pedro Güell un grupo de académicos de la (entonces) Facultad de Ciencias Sociales de nuestra Universidad en diciembre del año 2000. Aunque haya salido ya un nuevo Informe sobre Desarrollo Humano, nos parece pertinente dar a conocer estas reflexiones y compartirlas con nuestros lectores. 


\section{Conversación}

Pregunta: ¿Qué desafíos se presentan cuando se intenta por un lado desde las Ciencias Sociales estudiar el "Desarrollo Humano" y, por otro, ofrecer evidencias que puedan ser aplicables a distintos contextos sociales; a estudios cuyos resultados traspasen las fronteras?. ¿Qué estamos entendiendo por el concepto el desarrollo humano?

PG: En términos conceptuales Desarrollo Humano es aquel proceso que permite la ampliación de las oportunidades de las personas; oportunidades para hacerse más personas. Con esto se quiere decir dos cosas. En primer lugar, que hay que reivindicar el humanismo como horizonte del desarrollo y, en segundo lugar - aunque estratégicamente resulte lo más importante - que es necesario criticar el mito que se oculta tras la idea que el crecimiento económico de los países es un fin en sí mismo al cual deben subordinarse otros fines e, incluso, la forma misma del orden social. El desarrollo humano no ha ido ni va necesariamente de la mano con el crecimiento económico.

Hay suficientes evidencias recientes que sugieren un distanciamiento entre desarrollo humano y crecimiento económico. Hacia fines de los 80 se descubre que es posible tener crecimiento económico, lograr eficiencia institucional y, sin embargo, generar procesos de desintegración social, de pobreza, de desmovilización. Este dato, de gran interés para la reflexión sociológica dentro del informe, muestra que la denominada "década perdida" no es sólo pérdida desde la perspectiva económica que es la perspectiva que siempre se enfatiza - sino que puede ser leída como década perdida de la perspectiva de la fortaleza de la sociedad.

Es en ese contexto que nace el concepto de Desarrollo Humano. Él se refiere al acumulado de oportunidades disponible para la personas en la forma de organizarse la sociedad. En esa perspectiva no todo es oportunidad, sino aquello que aumenta las capacidades de las personas para realizarse como tales en sus vidas cotidianas. Se refiere al conjunto de transformaciones no sólo económicas, sino también de aquellas transformaciones políticas, jurídicas y culturales que permiten aumentar esas capacidades. 


\section{Conversando con Pedro Güell}

Este concepto así construido es tomado como la base para relanzar una Agencia de Desarrollo que no quiere ser meramente un banco multilateral o una agencia donante. El Programa de Naciones Unidas para el Desarrollo plantea que es posible y necesario hacer una articulación entre financiamiento, desarrollo y fortalecimiento social. Estos son los elementos que se traducen de manera bastante preliminar en el informe mundial de 1990 gracias a una muy fructífera colaboración de personas e instituciones académicas de prestigio mundial.

Hacer operativo el concepto de desarrollo humano representaba una gran dificultad. Este concepto entendido como proceso de ampliación de las oportunidades de que disponen las personas es un concepto muy amplio. Ello hace que su operacionalización empírica sea relativamente pobre. Era necesario determinar cuáles eran los indicadores empíricos del desarrollo humano. Una dificultad no menor radicaba en buscar el máximo común de indicadores disponibles en y entre países, teniendo como meta medir empíricamente este fenómeno, tarea que hasta entonces no se había realizado, y menos aún simultáneamente para 130 países. Este indicador, por tanto, necesitaba ser construido a partir de estadísticas disponibles, comunes y comparables en todos aquellos países. Para ilustrar las dificultades, no sólo estamos tratando de comparar Chile con Argentina y Uruguay; estamos por ejemplo comparando Nicaragua con el Chad y Estados Unidos, es decir, algunos países cuyas estadísticas nacionales son extremadamente precarias e inciertas.

Pregunta: ¿Cómo es posible conciliar la labor del sociólogo, con la formación, intereses y utopías?, ¿Qué opciones de cambio y qué intereses sociales estaban en juego?

P.G: Crear conceptos en el escenario de las Agencias Multilaterales de Desarrollo es siempre una operación estratégica. Es decir, no solamente se genera aquel concepto que da cuenta intelectualmente de los fenómenos de la manera más adecuada, sino que es necesario también crear aquel concepto con el cual instituciones y personas con distintos intereses están dispuestas a comprometerse. Un concepto de desarrollo en el contexto de las agencias internacionales es siempre la búsqueda de un espacio para la acción de esas mismas instituciones, y esto supone 
reconocer sus posibilidades y limitaciones. En este caso hay que reconocer que el PNUD hizo un esfuerzo exitoso por validar un concepto que no sólo era estratégico, sino que además contenía una enorme capacidad para interpretar las nuevas tendencias.

Esta constatación nos lleva a hacer una diferencia entre el trabajo puramente académico, al que como cientistas sociales estamos más acostumbrados; y aquel trabajo intelectual destinado a reunir capacidades de interpretación con voluntades de acción. En este contexto, un concepto que deja fuera a los aliados que pueden colaborar en la realización práctica de la utopía que lo inspira es un concepto precario aunque intelectualmente sea bueno. A este requisito, siempre difícil de cumplir, se le suma la complejidad metodólogica que ofrece la construcción del concepto de Desarrollo Humano en una perspectiva estrictamente sociológica.

En concreto, lo anterior significaba asumir en algún grado el supuesto instalado por esos años en las agencias multilaterales de que el mercado es el gran creador de oportunidades. Adicionalmente primaba en ese escenario una cierta orientación antiestatista. Recordemos que en el debate sobre el desarrollo de fines de los ochenta se tiene en mente el escenario de la crisis del mundo soviético, así como también de las experiencias dictatoriales latinoamericanas. Ello tendió a conducir a una suerte de rechazo a todo lo que pudiera asociarse con la existencia de un Estado fuerte que coarta las libertades de sus ciudadanos. El problema para ese debate es el paso muy rápido desde el miedo a que los Estados coartan la libertad hacia la afirmación de que los mercados producen, por el sólo ejercicio de su actividad, más libertad social.

Otro elemento que no se puede omitir en la génesis del concepto de desarrollo humano es la historia de las consecuencias políticas no deseadas que se derivaron de las propias iniciativas de las agencias de desarrollo. Por ejemplo, algunos proyectos de apoyo a la descentralización de los recursos nacionales y su desplazamiento hacia espacios locales terminaron fortaleciendo las oligarquías y mafias locales en vez de apoyar la descentralización o a las organizaciones de la sociedad civil. Malas experiencias en este campo llevaron, por ejemplo, a una afirmación relativamente tímida de procesos de descentralización y de participación 
social.

Así como el temor a la experiencia reciente con los Estados decantó demasiado rápidamente hacia una afirmación acrítica del mercado, así también la dificultad para controlar los procesos sociales vinculados a proyectos de desarrollo decantó en un cierto temor a la participación.

Como podemos ver, el concepto de desarrollo humano se genera en un escenario histórico específico. El está marcado por el debate sobre quién hace y para quién se hace desarrollo humano, así como por los temores surgidos de las experiencias anteriores en relación a esas mismas preguntas. Metafóricamente, este concepto se definió al mismo tiempo y a la misma velocidad con que se cayó el muro de Berlín, así como con las mismas ansias y temores que orientaron ese proceso. Ello se expresa en la intención del concepto de desarrollo humano de facilitarle a la población de esos países las condiciones para que desplieguen su creatividad y puedan hacerse autosubsistentes, limitando de paso la búsqueda de algunos de un mayor protagonismo estatal. Con algunos matices propios, la historia de los desafíos de la transición latinoamericana a la democracia, sueños y fantasmas incluidos, jugó un rol similar en el surgimiento del concepto.

En esta historia la preocupación de la cooperación internacional para el desarrollo y, por tanto, de los conceptos que están asociados a ella, es ¿cómo hago yo, Agencia, para darte unos dólares y que al cabo de dos semanas tú no me vuelvas a pedir más?, ¿Cómo lograr que el apoyo económico conduzca a la autosubsistencia?. Este último componente, la capacidad de promover la autosustentabilidad de los proyectos, lo cual hace parte del concepto del desarrollo humano, resultó una idea muy atractiva para los aliados en la cooperación internacional, siempre temerosos de que su ayuda cree más dependencias de las que quieren evitar.

Pero más allá de ese contexto inicial que marcó el concepto, el propio debate posterior y nuevas constataciones lo hicieron evolucionar. El concepto de desarrollo humano se ha ido despojando de un cierto individualismo ingenuo que lo caracterizó en sus orígenes, así como de una 
cierta distancia respecto de la participación social y de la política. En ello ha jugado un rol crucial la idea de que el desarrollo de las capacidades personales requiere de un "ambiente social favorable y propicio". Ello es analítica y empíricamente relevante, pues invita a develar las características o atributos de ese ambiente: ¿cuáles son las condiciones sociales que provocan, producen o facilitan el desarrollo humano?. Con ello el debate sobre el aumento de las capacidades individuales se vuelca a la pregunta por la relación individuo-sociedad.

El concepto de desarrollo humano en su origen dice que hay que aumentar las oportunidades para las personas. Por un lado acepta que esas oportunidades las produce el mercado, como también una buena asignación nacional de recursos, la gobernabilidad política y un régimen democrático. La evolución desde un cierto individualismo ingenuo que puede albergarse en esa idea surge desde la constatación que no basta con que los sistemas produzcan oportunidades ya que es necesario también asegurar que los individuos tengan las capacidades para aprovecharlas. Es a partir de esta constatación que se incorporará un debate sobre "las condiciones del ambiente" que habilitan o inhiben a los individuos para la creación y aprovechamiento de las oportunidades sociales. Se puede apreciar que un giro importante en el concepto de desarrollo humano se refiere a las relaciones de complementariedad entre desarrollo individual y desarrollo social.

Pregunta: Puedes decirnos algo más sobre la libertad política, la libertad de las primeras definiciones de cómo incorporarla en este indicador.

P.G: La libertad política está muy al centro de las reflexiones conceptuales de desarrollo humano. Eso es coherente con la inspiración post-estatista del concepto. Por lo mismo, desde el inicio los informes mundiales de desarrollo humano han estado muy pendientes de todo aquello que coarta la libertad individual. Largas reflexiones y observaciones se han dedicado a los derechos humanos, a la libertad política, a la libertad cultural, a la libertad de expresión, a la libertad de emprendimiento.

Los informes han hecho algunos esfuerzos por cuantificar comparativamente las libertades. Pero como es obvio esto es extremadamente difícil 


\section{Conversando con Pedro Güell}

por dos razones. Están, por una parte, las dificultades propiamente de medición. No es fácil definir cuáles son los indicadores empíricos de las distintas dimensiones de la libertad. Menos aún elaborar indicadores que tengan igual sentido y validez a través de las distintas culturas que considera el informe mundial. Aun si se llegará a definiciones de validez universal, probablemente no se dispondría de las fuentes de datos necesarias para cuantificarlas. Si ya es un problema medir con certeza el grado de escolaridad de las distintas poblaciones, más engorroso sería decir algo sólido sobre indicadores tan subjetivos y normalmente silenciados como los de la libertad. Por otra parte hay dificultades de tipo político. Los resultados de un índice comparado de libertades políticas o religiosas, por ejemplo, resultaría, sin duda, intolerable para una buena cantidad de gobiernos a lo largo del mundo. El riesgo de perder la disposición de los gobiernos a recibir el informe tendría un costo muy alto en la política del PNUD y en la eficacia de los foros internacionales de desarrollo promovidos por él. Menos aún vale la pena el riesgo si está fundado en un indicador precario.

Pregunta: ¿qué significado tiene el capital humano para el desarrollo humano?

P.G: Invertir en capital humano significa aumentar las capacidades de los individuos para crear y aprovechar riquezas en el contexto de los sistemas económicos. En los primeros informes del PNUD se establece una distinción entre capital humano y desarrollo humano. El problema captado relativamente temprano es que nada asegura que los individuos, aun cuando aumenten sus capacidades de captar oportunidades, por ejemplo a través de la educación, estén en condiciones de presionar a los mercados y a los sistemas sociales para que produzcan oportunidades relevante para ellos. El concepto de capital humano, siendo importante para destacar requisitos indispensables de la economía moderna, no ilumina suficientemente un problema crucial para las sociedades que albergan a esas economías. Los mercados y sistemas modernos crean recursos y producen formas de riqueza que no necesariamente son una oportunidad para el desarrollo de la sociedad como un todo.

El gran tema olvidado tras la idea de capital humano es cómo los indi- 
viduos se transforman en actores capaces de determinar en algún grado la dirección de los sistemas y cómo se asegura que los productos de los sistemas se transformen en oportunidades para todos los individuos y para el desarrollo político de la sociedad en que viven. Por tanto, el gran tema olvidado es ni más ni menos la sociedad y la capacidad de autodeterminación de los actores sociales. Pero no hay que exagerar. El concepto de capital humano es restringido a la vida económica y ha cumplido un papel relevante ahí. Lo que hay que cuidarse es de extrapolar su sentido como una pretendida forma de valorar la sociedad. El concepto de capital humano se refiere al aumento de capacidades de operación de las personas al interior de la lógica de los sistemas. A la sociedad se la valora y reconoce adecuadamente cuando se pone en el centro su vocación de autodeterminación. Y, a veces, entre adaptación funcional y autodeterminación hay una distancia muy grande, para decirlo sociológicamente.

Lo que han pretendido los debates posteriores del concepto de desarrollo humano es precisamente poner en el centro la idea de capacidades y oportunidades para el aumento de la autodeterminación social. Esta innovación va a permitir la entrada masiva de las Ciencias Sociales en la elaboración de los informes del desarrollo humano, especialmente a nivel de informes nacionales.

Como mencioné recién, lo que permitió esta reorientación desde la economía hacia las ciencias sociales es la consideración de aquel "ambiente propicio" que hace posible el aumento de capacidades individuales. Inicialmente ese ambiente estaba pensado como democracia, libertad, tolerancia, suponiendo que estas son las condiciones en las cuales un individuo puede aprovechar las oportunidades creadas por la economía y las instituciones sociales. El concepto de ambiente propicio se va perfilando luego en un sentido más complejo y más actualizado a los desafíos del presente. Así, en los informes chilenos de desarrollo humano, el "ambiente propicio" es entendido como el conjunto de condiciones sociales que permite que los productos de los sistemas, cada vez más autorreferidos, se transformen en oportunidades para los individuos y, que a su vez los individuos se transformen en sujetos capaces de captar y redefinir oportunidades a través de su acción sobre los sistemas. 


\section{Conversando con Pedro Güell}

La tarea pendiente es determinar cuál es el modo de organización de las relaciones sociales o ambiente propicio que hace posible que se sintonicen dos aspectos que no se sintonizan espontáneamente: los sistemas productores de recursos, por una parte, y los procesos productores de subjetividad, por la otra, aquellos procesos que están llamados precisamente a definir el sentido de la convivencia social y a definir las capacidades y oportunidades requeridas para la realización de ese sentido.

La articulación de estos dos mundos, el de los sistemas sociales y el de la subjetividad, es también una tarea pendiente para la teoría sociológica. La Teoría del Desarrollo que se inicia en los años 50', concibe al desarrollo como un despliegue de una cierta dinámica social gracias a la transformación de las estructuras que la organizan y contienen. En ese entonces el problema era determinar qué estructuras transformar para desatar la dinámica social deseada. Las teorías del desarrollo dieron por supuesto varias cosas: que la sociedad existe, que su dinámica determina los procesos de cambio y que los sistemas de coordinación social son estricta y únicamente sistemas sociales. La sociedad existe, es determinante de la forma del desarrollo y lo que hay que hacer para conseguir el desarrollo deseado es cambiarla en sus dinámicas propiamente sociales.

Hoy día estamos en una situación perfectamente inversa, lo que se da, por supuesto, es el cambio y lo que no puede ser dado, por supuesto, y debe ser construido es la sociedad. Lo que define la forma del cambio es la dinámica autorreferida de los sistemas de la sociedad. Lo que está en cuestión hoy día en la Teoría del Desarrollo no es el cambio, sino la construcción de aquella sociedad que es capaz de modelar el cambio. Necesitamos de una sociedad que sea capaz de transformar este cambio en otra cosa, porque las dinámicas de autonomización del cambio fueron extremadamente fuertes. La pregunta sociológica básica que se puede levantar es ¿cuál es el núcleo social del ambiente propicio?, ¿cuál es el tipo de ambiente que se requiere para mediar entre los sistemas que producen recursos y la subjetividad que define lo que es una oportunidad?. Los informes chilenos de desarrollo humano han intentado responder sucesivamente a estas preguntas. Se han preguntado por la existencia de la certidumbre y la inseguridad en Chile, por la densidad de nuestro capital 
social, de nuestra ciudadanía y del proceso de reflexividad social.

Pregunta: Yo veo que en esa nueva definición de cambio está implícita la necesidad de mantener una sociedad con la capacidad de reproducirse y de conducirse; entonces ¿Hay un componente ético fuerte en la construcción del concepto de desarrollo humano?

P.G: Me parece muy interesante tu pregunta porque permite introducir otra complejidad en nuestra conversación. Hay aparentemente unos elementos que son éticos y otros que no lo son. Hay temas de gobernabilidad o de sustentabilidad que podrían ser derivados de una mirada estrictamente funcional. Por ejemplo, si no otorgamos fuentes de legitimidad a la política se puede debilitar la democracia o si consumimos más energía que la que podemos crear nuestra existencia tiene un límite. Esas reflexiones son estrictamente funcionales no requieren necesariamente de un horizonte ético. Distinto es cuando nos hacemos las preguntas ¿para qué queremos democracia? o ¿por qué debemos asegurar condiciones de supervivencia a las nuevas generaciones?. En el concepto de desarrollo humano conviven y se relacionan los dos niveles. La inspiración humanista del concepto hace que se ponga precisamente el énfasis en la necesaria justificación ética de la imagen de desarrollo. Es decir, la pregunta qué, cómo y cuánto producimos se subordina a la pregunta para qué y para quién producimos. No se podría afirmar que la subjetividad personal y social es la finalidad del desarrollo sin al mismo tiempo afirmar que su justificación depende de una ética.

Podemos decir que, desde una perspectiva sociológica, el concepto de desarrollo humano es tradicionalmente moderno. El principio básico de la modernidad es la autodeterminación o la oferta de autodeterminación de la sociedad y de las personas por sí mismas. Esa oferta no puede sostenerse mediante un análisis puramente funcional o sistémico. El desarrollo humano recoge esa afirmación originaria de la modernidad. Lo contrario es lo que ocurre con las teorías de la globalización o del caos entendidas como ideologías de la irresponsabilidad. Allí se afirma que dado que los procesos globalizados o sistémicos escapan por su complejidad a la capacidad de la sociedad para conducirlos entonces lo que hay que hacer es adaptarse. Salvo que pudiera formularse una ética 


\section{Conversando con Pedro Güell}

de la adaptación, los relatos de la irresponsabilidad se contentan con el análisis funcional.

Esta afirmación ética que está en el origen de la modernidad, y que el concepto de desarrollo humano hace suya, nos remite también a ciertos temas básicos de la sociología clásica. La pregunta que se plantearon sociólogos como Durkheim, Simmel o Weber es ¿cómo, en condiciones de complejización y diferenciación de la sociedad, ésta es capaz de mantener un núcleo autónomo para su integración? Es decir, ¿cómo somos capaces de mantener la existencia del vínculo social más allá de las presiones de funcionalización que exigen las nuevas tendencias modernas? Por ejemplo, recordemos la reflexión sobre la jaula de hierro de la racionalización en Weber, o la discusión sobre la reciprocidad del don o la reciprocidad de mercado en Durkheim. Este último nos muestra la necesidad, incluso funcional, de mantener un núcleo de reciprocidad cuyo contenido es una moral social. En la actualidad si no somos capaces de mantener este núcleo de reciprocidad social, obviamente tampoco seremos capaces de conducir y aprovechar los nuevos fenómenos de diversificación y complejización. Por el contrario, como sugeriría Durkheim, estaremos amenazados de desintegración. El punto común entre las preocupaciones de la sociología clásica y las de nuestra época es que la sociedad no es el resultado espontáneo de las dinámicas de intercambio motivadas en el interés individual, sino que hay que hacer un esfuerzo intencional y colectivo por constituir una integración que tiene sus propias reglas. Desde esta perspectiva la pregunta actual por el orden está vinculada con la acepción clásica. Ella nos remite a que la sociedad existe por sí sola, que tiene reglas propias y, por lo tanto, exige esfuerzos específicos para construirla o reconstruirla.

Esta actualidad sociológica de la pregunta por el orden se expresa, por ejemplo, en debates muy concretos surgidos a raíz de los informes chilenos. Uno de ellos es el debate con el neoliberalismo sobre el fundamento de la confianza social. Estos sostienen que el aumento de las interacciones e intercambio de mercado produce por sí solo el quantum de confianza que esas interacciones requieren para funcionar. En nuestra opinión eso no es efectivo. El mercado supone la existencia de una confianza que no es capaz de producir por sí mismo. Si recordamos a Durkheim, podremos 
afirmar que el contrato depende de condiciones precontractuales que el propio contrato no puede crear. La confianza remite al carácter moral y sui géneris del vínculo social, lo cual supone, entre otras cosas, una imagen simbólica de un Nosotros que me vincula a mí mismo y al Otro. Eso es anterior al mercado y exige una afirmación de la autonomía de la sociedad.

Lo contrario, que es precisamente la apuesta sociológica del neoliberalismo, si es que acaso el neoliberalismo puede tener una sociología, es la pretensión de que el mercado no sólo asigna recursos y define preferencias, sino que además funda el vínculo social. Gracias a una economía de mercado, y por el sólo efecto de sus dinámicas, seríamos capaces de fundar un proceso de integración, de intercambio, de reciprocidad, de confianza, el cual surgiría como resultado espontáneo de sucesivos intercambios. Tampoco sería necesario justificarlo, porque mientras existan el hambre y la necesidad de reproducirse, los intercambios van a ser necesarios.

La pregunta es si a la sociedad hay que producirla desde sí misma o si la sociedad es el resultado espontáneo de procesos extrasociales, tales como los económicos. El debate en torno a las posibles respuestas tiene un profundo significado político. La respuesta es clave ya que tiene impactos concretos. Por ejemplo, sobre cosas tan concretas como cuál es la política comunicacional que debe tener un Gobierno. El dilema es sí hay que favorecer procesos de comunicación que permitan la coordinación social o la comunicación es el resultado espontáneo de personas que buscan sus propias oportunidades; ¿el mercado produce las palabras o las palabras vienen de otro lado y son necesarias para el mercado?

También tiene un impacto sobre el concepto de políticas públicas. Una manera es concebirlas en función de su eficiencia económica medida en términos de los valores agregados netos y de las tasas internas de retorno. Otra manera es evaluarla en función del quantum de sociedad que producen, del capital social que se genera como efecto de una política pública. La diferencia entre ambas es la respuesta al pregunta ¿debe la sociedad producir intencionalmente a la sociedad o debe sólo asegurar la fluidez de los intercambios privados? 


\section{Conversando con Pedro Güell}

Pregunta: En este breve recorrido histórico, el concepto de desarrollo humano va a avanzar hacia la pregunta sobre ¿Cómo generar esta sociedad que es capaz de mediar entre sistemas productores de oportunidades, cada vez autonomizados y una sociedad también en términos divididos cada vez más automonizada, individualizada? La eventual respuesta nos remite a la pregunta por el sujeto, a la pregunta por el orden y por la subjetividad.

P.G: En los informes Chilenos el concepto de subjetividad hace referencia a esa sociedad consciente de sí misma, que se plantea el objetivo de ser actor reflexivo en función de vincular los procesos entre individuo y del sistema. Subjetividad social alude a una sociedad que quiere hacerse cargo de sí misma y que tiene como sentido y fundamento la autodeterminación.

La pregunta por el sujeto social es acuciante tanto en la sociología como en la filosofía y en la sicología social. Se refiere precisamente a si es aún posible afirmar la existencia de una autodeterminación intencional y reflexiva de la sociedad por sí misma. La globalización, el fin de las ideologías y la complejidad de las nuevas organizaciones le han quitado el piso a las nociones de sujeto social propias del siglo XIX y de la primera mitad del XX. ¿Quién puede hoy determinar intencionalmente el orden social, con qué conocimientos, desde qué punto de vista, con cuál poder? La respuesta desde hace varias décadas es: nadie. Luego, los individuos tienen que realizar sus sentidos propios buscando adaptaciones exitosas o desadaptaciones radicales a las dinámicas de los sistemas.

Esa afirmación, que algunos llamarían escepticismo postmoderno, suena demasiado funcional a los intereses de aquellos que quieren autonomizar el flujo de los mercados de las demandas sociales como para no sospechar que tiene mucho de ideología. La idea de subjetividad levantada por los informes de desarrollo humano pretende afirmar que no se puede renunciar sin más a la idea de la autodeterminación social. Pero quiere afirmar también que no se puede ser ingenuo y afirmar la idea clásica de sujetos sociales tales como clases, movimientos o partidos. En nuestro caso subjetividad alude a la imagen de un nosotros social que circula y se construye en el espacio de los vínculos, conversaciones y aspiraciones cotidianas de las personas. La transformación de eso en sujeto es 


\section{REVISTA CHILENA DE TEMAS SOCIOLÓGICOS}

precisamente la ciudadanía. Se trata, sin embargo, de sujetos difusos e inestables, tanto como la propia vida cotidiana.

Hay que reconocer que esa idea de subjetividad no es, por ahora, más que un punto de partida que ha permitido apuntar acertadamente a ciertos aspectos y problemas de nuestra realidad actual. Como por ejemplo, que las dinámicas de la subjetividad no se orientan necesariamente por las dinámicas y resultados de la economía o de la política y que ese divorcio puede ser un obstáculo tanto para la primera como para la segunda. Ello nos permite afirmar que hay que preocuparse de la subjetividad social en cuanto tal y no sólo de los resultados económicos. A su vez, ello permite reponer el tema de la autonomía y autodeterminación como demanda de la subjetividad. En cualquier caso, hay que discutir mucho más este concepto. Después de muchos años en que se hizo una crítica radical a las teorías del sujeto y en que tendimos a creer que el tema del sujeto social estaba superado, hoy nos damos cuenta que tal vez fuimos demasiado lejos y que debemos reponer el tema en las actuales y específicas condiciones de la globalización y de la complejidad de lo social.

Pregunta: Cuéntanos un poco cómo se vivió el proceso, ¿cómo se gestaron los cuatro informes en Chile?

P.G: Voy a describir los cuatro informes chilenos de manera muy simple. Obviamente partimos tímidos, no porque supiéramos poco del tema, sino porque no sabíamos cómo se iba a recibir el informe y queríamos instalarlo correctamente. Entonces, la primera pregunta que nos hicimos apuntó a una aspiración muy sentida y con baja conflictividad política: la regionalización. Si en Chile hay un crecimiento aceleradísimo, ¿cómo llega este crecimiento a la región?, ¿cómo se distribuye el crecimiento económico y la modernización de los sistemas a lo largo de Chile? Ese informe de 1996 descubre la macrocefalia de la región metropolitana. No obstante, en esta primera entrada nosotros dijimos, no basta con decir que las regiones reciben poco, o cuánto son capaces de captar, -que es una pregunta que viene de tiempo atrás-, había que preguntarse también por la capacidad propia de las regiones para demandar del centro una reconversión, una redefinición en los términos de distribución del desarrollo. Entonces, y en relación con la descentralización y a la 


\section{Conversando con Pedro Güell}

participación local, nos hicimos, al mismo tiempo, la pregunta por la existencia de capacidades en las sociedades locales para moldear sus entornos. Aquí todavía no era un tema político, era un tema muy técnico. Hicimos desagregación del gasto regional por primera vez, hicimos una observación de competitividad regional, también por primera vez. Hicimos una observación de las capacidades institucionales de las regiones, es decir, grupos de presión, de élites, sus instituciones políticas, gubernamentales, universidades, generación de conocimiento, en suma, qué capacidad tienen las regiones de producir regionalización, no sólo descentralización. No hay descentralización sin regionalización, es decir, no se puede forzar al centro a distribuir los recursos de manera distinta, de crear condiciones distintas, si no hay un sujeto regional, o procesos de subjetividad regional que crean en el futuro regional, que sepan donde quieren ir, y que estén dispuestos e interesados en asumir cuotas de poder.

De esos estudios surgió la impresión de que las regiones eran extraordinariamente débiles en su capacidad de regionalización, y que a lo más, en Chile había posibilidad de descentralización a partir de la buena voluntad del centro. Parece existir una baja capacidad en las regiones para definir sus demandas frente al estado central, condiciones que, a mi juicio, no han cambiado mucho después de aproximadamente cinco años de la publicación de ese informe. Existen, a nivel regional, sociedades civiles extraordinariamente débiles, que no han sido capaces de captar, ni de presionar, a los sistemas y a los gobiernos centrales, para la obtención de mejores condiciones.

A pesar de que el tema aparecía tímidamente, ahí nos empezó a dar vuelta la idea de que en este país la sociedad estaba por un lado y los sistemas de producción de recursos y de coordinación por el otro. Nos comenzaba a llamar la atención lo que finalmente llamamos la paradoja de la modernización. Cómo se explica este país, ya en el año 96', cuando estábamos produciendo este informe, con un crecimiento del producto, mayores oportunidades, modernización institucional, modernización jurídica, relativo orden y tranquilidad social, pero, sin embargo, con síntomas crecientes de malestar, una especie de incomodidad difusa. Vimos que detrás de esto estaba la relación entre sociedad, subjetividad y los 


\section{REVISTA CHILENA DE TEMAS SOCIOLÓGICOS}

sistemas. Este es un tema central para el desarrollo humano, además de ser fundamental para ampliar el concepto.

Ante las desconfianzas respecto a nuestras reflexiones, pudimos mostrar empíricamente en el Informe del 98' que esa percepción de distancia entre sociedad y procesos de modernización tenía asidero. Ello fue posible gracias al análisis empírico de la seguridad humana en Chile. Este concepto de seguridad humana decía que era aquella situación en la cual las personas tienen las condiciones que les permiten efectivamente desplegar sus capacidades, y sobre todo, la seguridad de que esas condiciones no van a desaparecer. Entonces, nosotros apostamos a que lo que estaba ocurriendo en Chile eran procesos masivos de incertidumbre, es decir, que las personas tenían la sensación de que, por la velocidad de producción de estas oportunidades, por el tipo de producción de estas oportunidades y por la forma de su distribución, ellas no eran percibidas como productoras de seguridad, sino incluso lo contrario. Decidimos investigar esto. Descubrimos tres grandes temores. El primer temor era a los sistemas sociales productores de oportunidades que eran percibidos como altamente selectivos, es difícil subirse a ellos y muy fácil bajarse. Pensemos en una AFP o en una Isapre, pero también hay un conjunto de otros sistema que son observados por la gente en esta perspectiva.

Después hicimos, por primera vez también a nivel mundial, un índice de seguridad humana. En él medimos seguridad humana en términos objetivos, es decir, visto desde los sistemas y sus productos; esto es, cuánta seguridad tienen los sujetos en términos objetivos: contratos, rendimientos de AFP, comisaría cerca de la casa, ingresos, educación y capacitación, etc. Pero también estudiamos la perspectiva subjetiva de la seguridad: cómo perciben las personas las seguridades que tienen: redes sociales, tramas de seguridad. Los datos mostraron que si la seguridad objetiva era baja en Chile, la seguridad subjetiva era más baja aún.

Para analizar las consecuencias de este hecho introdujimos un concepto estrictamente sociológico: el teorema de Thomas. El teorema de Thomas dice que lo que las personas definen como real, es real en sus consecuencias. Eso es tan fácil como que si alguno de ustedes grita que hay un incendio y nosotros lo creemos, todos arrancamos escaleras abajo; da 


\section{Conversando con Pedro Güell}

lo mismo si hubo incendio o no, el hecho objetivo es que todos arrancamos empíricamente igual que si hubiera habido incendio. Entonces, el informe del '98 sugirió que si las personas definen que los sistemas no les brindan las oportunidades, las tramas sociales y las certidumbres que ellos requieren para operar en situaciones cada vez más inestables e inciertas, entonces se descuelgan de esos sistemas, y aquellos sistemas de los cuales las personas masivamente se descuelgan son sistemas no sustentables. Hay dos ejemplos chilenos recientes de la operación del teorema de Thomas. El primero son las Isapres; el exodo de afiliados desde las Isapres es muy grande, al punto que la gente está volviendo a sistemas como FONASA. Esto pone al límite la sustentabilidad financiera de las propias Isapres, porque la gente se sale. Lo mismo le pasaría a la Coca Cola el día que la gente perciba que la Coca Cola no es grata y no quita la sed. Si la gente percibe eso, la Coca Cola quiebra. Ese es el teorema de Thomas, pues a pesar de que la Coca Cola, empíricamente pueda tener los mismos componentes químicos de siempre, bastará que la gente lo perciba para que actúe en consecuencia. Que la Coca Cola quiebre puede no ser grave. Que las Isapres quiebren es más preocupante.

Pero lo que es realmente preocupante, y ese es mi segundo ejemplo de operación del teorema de Thomas, es la sustentabilidad de la democracia. En el momento que las personas perciban que la democracia es un sistema que no brinda las oportunidades que ellos quieren y requieren, se distancian de los mecanismos de acceso y participación en la democracia y la democracia dejará de funcionar como sistema, pues la democracia no es sustentable sin gente que se comporte democráticamente. Lo que podría hacer posible el quiebre de la democracia hoy no es tanto el fracaso formal de sus sistemas, sino el descuelgue de la ciudadanía. Nosotros medimos en el último informe, para adelantar datos, que a más del $50 \%$ de las personas, o le da lo mismo cual sistema, o prefiere uno no democrático en ciertas circunstancias. Esto muestra que las disposiciones de apoyo a la democracia en Chile por parte de la ciudadanía, son relativamente críticas. En el mismo sentido puede entenderse la tendencia de los jóvenes a excluirse de los sistemas electorales.

Esto puede ayudarnos a entender, tanto en el caso de Chile como en el 
de varios países de América Latina, la emergencia de neopopulismos de base neoliberal. Ellos proponen una nueva alianza entre élites y sociedad al margen de la política. Dicen, mira, hagamos un pacto tú y yo; tú déjame tranquilo el mercado y los sistemas, déjame tranquilas las preguntas sobre el modelo de desarrollo y yo te brindo oportunidades concretas en tu metro cuadrado, yo te hablo directo a ti, te amparo, te protejo, te doy oportunidades, semáforo, vereda, trabajo, pero tú déjame los otros temas. Es decir, el pacto entre tú y yo es sacar al tercero de la mesa, aquello que se llama política y sociedad organizada. Eso es populismo. El populismo siempre fue la desconexión del intermediario organizado, política y sociedad organizada, política y movimiento social, para entenderse directamente con la subjetividad herida de las personas. El populismo es un acto de amparo. Pero que a cambio exige la renuncia de los acaparados a pensarse a sí mismos como sociedad y, por lo tanto, con capacidad y derecho a determinar por sí mismos sus condiciones de existencia.

En esta oportunidad lo interesante del populismo emergente es que no hay una crítica del sistema económico. Por el contrario, dice ¡déjamelo tranquilo!, porque el mercado por sí solo nos va a producir las condiciones que requerimos para nuestro matrimonio, este matrimonio directo entre poder del Estado y subjetividad de los ciudadanos. Es un fenómeno que se está masificando, uno puede encontrar el caso chileno, que estuvo al borde del gobierno, y probablemente nos va a tener por las cuerdas en el futuro, y también es el caso de Menem, de Fujimori, de Chávez, en parte Alemán en Nicaragua.

Hay un fenómeno aquí que tiene que ver con que la forma de nuestra política no ha sido capaz de recoger la demanda de la subjetividad herida, y no ha sido capaz de transformar esa demanda en un proyecto político de autodeterminación social. Por poner un ejemplo, si ustedes ven a nivel de lenguaje cómo se trató la crisis Asiática en Chile, fue una discusión entre el Ministro de Hacienda y el Presidente del Banco Central. No hubo ninguna conversación sobre la crisis Asiática que pasara ni por la política, ni por la sociedad, y eso fue un refuerzo de la ideología o del mensaje de irresponsabilidad que hay detrás de la ideología de la globalización. Como no podemos hacer nada, entonces hay que adaptarse y sobrevivir 


\section{Conversando con Pedro Güell}

y dejar a otros que manejen aquellos instrumentos, los financieros, que según se nos dice son los únicos con los que se puede hacer algo. Eso explica una masa de subjetividad herida, acorralada, como la llamamos nosotros en los estudios, y que está disponible para un neopopulismo de base neoliberal muy astuto.

Lo interesante es que esta discusión nos permitió introducir en el concepto de desarrollo humano, una definición distinta de sustentabilidad que la que se estaba usando hasta ahora. Sustentabilidad significaba algo referido al medio ambiente: no consumas más recursos ambientales que aquellos que necesitas tú para vivir y que necesitarán tus hijos para vivir en el futuro. También estaba la noción de sustentabilidad de las agencias internacionales de desarrollo: yo te presto plata, pero por favor a vuelta de camino no me sigas pidiendo más, crea tu propios recursos para que puedas arréglatelas solo en el futuro. Para nosotros sustentabilidad implica producir procesos de complementariedad entre subjetividad social y sistemas tales que la propia subjetividad esté dispuesta a apoyar esos sistemas, lo que gracias a esto se hacen sustentables en el largo plazo. Nos parece que este concepto es central, entre otras cosas, porque la inestabilidad de los sistemas no es una enfermedad esporádica, sino que va a ser su característica normal. De ahora en adelante no vamos a hablar ya de la gran crisis del 30', de la gran crisis Asiática o la gran crisis del tequila, sino que vamos a decir, llegó la crisis de las seis de la tarde. La inestabilidad es un componente estructural de los sistemas autorregulados. Por lo mismo la mantención de las bases propias y autónomas de los vínculos sociales será uno de los recursos más importantes que las sociedades pueden exhibir para integrarse y sobrevivir exitosamente en los vaivenes de una sociedad globalizada.

Este concepto sustentabilidad social del desarrollo y de la democracia nos lleva a otro concepto sociológico: ciudadanía. No sólo de una ciudadanía entendida como la defensa de derechos y referida a las oportunidades individuales. Se trata más bien de la construcción de una ciudadanía que se haga cargo precisamente de defender aquello que está realmente en cuestión aunque no figure en ningún catálogo de derechos individuales: la existencia de una sociedad con capacidad de autodeterminación. Entonces necesitamos un concepto de ciudadanía capaz de reflejar no sólo 
al individuo, sino también los vínculos sociales. Es decir, forma parte de los deberes y derechos del ciudadano hacerse cargo de la fortaleza de los vínculos sociales y de las conversaciones sociales que permiten activar una sociedad, hacerse cargo de la sustentabilidad, de la orientación de los sistemas, etc.

Esto nos llevó a plantearnos la necesidad de hacer un informe propositivo sobre el problema de cómo se reconstruye la sociedad, cómo se fortalece la sociedad para moldear los sistemas en función de la sustentabilidad y la democracia. Por eso el título del informe 2000 es: "Más sociedad para gobernar el futuro". Para que nuestras reflexiones tuvieran sentido había que plantear el problema en las condiciones actuales. No tenía sentido volver a las teorías clásicas sobre el sujeto social o hablar de la reposición del estado de bienestar. Por eso es que buscamos aquellos aspectos que podrían permitir reconstruir subjetividad social más allá de la teoría de las clases, más allá de la vigencia de los metarrelatos ideológicos y más allá de los estados de bienestar.

Por esta razón introdujimos el tema de las aspiraciones sociales. Nos pareció que a partir de su innegable existencia cotidiana podían fundarse principios de acción colectiva. Pero no basta con tener orientación social a partir de relatos surgidos de la vida cotidiana. Hoy día hay que tener movilizadores de aspiraciones. Tener aspiraciones no es lo mismo que creer que esas aspiraciones son posibles y por lo mismo de ellas no se deriva automáticamente la acción colectiva. Hay muchos pasos intermedios que no pueden darse por existentes. Hoy día no se puede apostar sin más a los partidos políticos como los que tenemos, ni a los movimientos sociales, porque parecen no existir en Chile. En Chile la sociedad civil es algo que logra juntarse gracias a que invita el Estado. En busca de estos movilizadores capaces de transformar las aspiraciones en acción apostamos al tema del capital social. Entonces dijimos, apostemos más abajo de los movimientos sociales, a lo que hay incluso por detrás de un movimiento social: al capital social.

Tener aspiraciones y capacidades de movilización para realizarlas es un ingrediente necesario y bueno, pero no basta. De hecho las mafias sicilianas tienen exactamente lo mismo, grandes redes sociales, grandes 


\section{Conversando con Pedro Güell}

aspiraciones, grandes voluntades de acción. Es necesario asegurar que el ejercicio de esas capacidades y voluntades deriven en más sociedad democrática y no en menos. Eso es precisamente ciudadanía en el sentido en que discutíamos recién. Eso es el informe del 2000, la observación de la existencia de una dinámica sinérgica entre aspiraciones, capital social y ciudadanía. Se trata de un informe buena onda, optimista, porque quiere hacerse cargo de las críticas que abrió el informe del 98'.

La discusión actual de este informe, que ha sido muy buena, nos ha llevado a definir los temas del próximo informe. Hay algunos temas que emergen como muy importantes y poco trabajados, sobre todo en relación a cómo fortalecer la sociedad en las actuales condiciones. Nos ha parecido que la apuesta al capital social puede ser un poco ingenua, pues supone ciertas condiciones del vínculo social y del carácter colectivo de la acción que ese mismo concepto no ilumina correctamente. Tenemos la impresión que esos aspectos se refieren a la producción y reproducción de un sentimiento de pertenencia a un nosotros colectivo. Es por esto que hemos decidido dedicar el informe 2002 a la cultura y al cambio cultural. Para ello tenemos la siguiente hipótesis gruesa: en Chile tenemos un imaginario cultural sobre lo que somos, cómo somos, y qué debemos hacer. Pero ese imaginario no parece corresponderse ya con lo que efectivamente somos, con lo que efectivamente queremos hacer y con lo que efectivamente podemos hacer. Eso limita seriamente nuestras capacidades de acción colectiva.

Hemos cambiado en estos 25 años en relación con nuestro imaginario cultural. Esto tiene dos problemas. El imaginario heredado sobre nosotros no logra dar sentido a lo que la gente está haciendo cotidianamente, a sus prácticas. Esto produce un fenómeno de perplejidad cultural que no permite que las personas efectivamente desplieguen las acciones que son adecuadas a sus aspiraciones. Sabemos, por ejemplo, que ha cambiado enormemente la forma en que los electores se relacionan con el voto. Pero no sabemos qué significa eso para la democracia, cuales son las oportunidades y amenazas de ese cambio. Nos cuenta respondernos, pues estamos aún fijados en el imaginario tradicional que nos dice que a los electores hay que entenderlos bajo el prisma de la relación patrón-cliente o bajo el prisma de un militante leal a discursos ideológicos. Lo mismo 


\section{REVISTA CHILENA DE TEMAS SOCIOLÓGICOS}

ocurre en relación a las nuevas prácticas familiares, a la televisión, al consumo, etc.

Entonces, este será un informe de desmitificación sobre nosotros mismos. Quiere decirnos que hemos cambiado culturalmente de tal manera que es mejor que nos hagamos cargo de nosotros mismos ya, porque si no vamos a dejar pasar las oportunidades y vamos a ceder ante los riesgos que contienen las nuevas prácticas que estamos desplegando. Pero para eso necesitamos hacer un trabajo cultural, es decir, necesitamos trabajar una actualización de nuestros imaginarios. En el nuevo informe entendemos cultura en un sentido antropológico. Cultura son los modos de convivencia y la representación que nos hacemos acerca de la convivencia. Pero también queremos hacernos cargo de las tendencias de autonomización que hoy afectan a la cultura a caballo de la llamada "industria cultural". ¿Qué oportunidad y que amenaza hay en que los productos del sentido se transformen en un objeto intercambiable en el mercado? Estamos haciendo un mapa de la circulación de los Bienes culturales en el mercado Chileno.

Estamos investigando no sólo el tema de la objetividad de la circulación de los productos culturales, sino también el tema de lo imaginario en determinados campos como familia, trabajo, consumo, tiempo libre, sexualidad, pareja. Hay buenos datos si uno los rastrea y sobre todo si tiene un buen marco para integrarlos. Esa es una de las maravillas que nos ofrece el informe de desarrollo humano, la flexibilidad de poder integrar por ejemplo los resultados de la encuesta del comportamiento sexual de la CONASIDA con el estudio sobre bienes culturales del Banco Central.

El imaginario nuestro, es decir, el imaginario tradicional no explica el sentido de lo que de hecho somos y hacemos en nuestras prácticas. Como no tenemos un imaginario colectivo que nos explique, que nos interprete, que nos dé sentido, entonces, buscamos la explicación sobre nosotros mismos en la sicología de las personas. Así, nos decimos que lo que nos pasa tiene que ver con que los Chilenos son depresivos, trabajólicos, egoístas, etc. Eso no es un imaginario colectivo, eso es un imaginario de sumas de caracteres.

Pregunta: ¿Qué han descubierto? 
P.G: La pregunta por las novedades que nosotros nos hacemos es si hay algo nuevo que esté emergiendo y que sirva como marco de autointerpretación para la propia sociedad. ¿Cuáles son las nuevas identidades colectivas? Eso empíricamente es muy problemático, porque si hay algo emergente, es probable que su aparecimiento en el lenguaje público sea muy débil. ¿Cómo se detecta algo que incluso muchas personas ya lo están viviendo y que, sin embargo, no lo han transformado aún en lenguaje? No hay que olvidar que los estudios culturales son básicamente estudios de las distintas gramáticas de la sociedad; es decir, de los fenómenos sociales a través de sus expresiones lingüísticas, incluidos los símbolos. Para superar este problema estamos llevando adelante una serie de estudios cualitativos que usan elementos proyectivos, como fotos o dibujos. Porque estudiar representaciones prelingüísticas supone métodos proyectivos.

Estamos también tratando de incorporar un mapa de las tribus culturales que existen hoy en Chile, como otra manera de diagnosticar identidades emergentes. También estamos tratando de ver si efectivamente el consumo hoy día es un marco imaginario capaz de representar lo que la gente desea, lo que la gente se imagina sobre sí misma. O si la televisión es la nueva forma de lo público. Lo otro, y que es lo que más nos ha costado desarrollar empíricamente, es cómo se han transformado las formas de conversación entre los chilenos.

Uno de los instrumentos estelares de este informe será la elaboración de un mapa de los estilos de vida en Chile. Vamos a mapear empíricamente los distintos segmentos de población en función de sus prácticas y representaciones cotidianas. Estilo de vida es un concepto muy complicado, no tanto en su definición sino en su medición. Porque estilo de vida no es igual a criterio de segmentación en relación a las ofertas del mercado, que es lo que miden las empresas de marketing. En fin hemos avanzado bastante y, además, no les voy a contar cuáles son todos los resultados porque, si no, después no lo van a querer leer.

Pregunta: Respecto del tema de los imaginarios perdidos ¿por qué partir de la idea que los procesos sicológicos individuales no pueden reemplazar lo colectivo? 
P.G: Tenemos una hipótesis: la individualización de la vida personal es buena, forma parte de la promesa de autodeterminación moderna. Pero la individualización supone recursos y complementos que son estrictamente sociales. Ellos permiten, por una parte, que las personas puedan efectivamente construir sus proyectos de vida de manera autónoma y, por la otra, que efectivamente la alta individuación o la diversidad de las tribus no derive en fragmentación sino en más sociedad. En Chile tenemos un proceso de individuación extraordinariamente acelerado que no está siendo acompañado simultáneamente por la producción de las condiciones sociales para transformar esa individuación en más personalización y en un desarrollo de los vínculos sociales.

Pregunta: ¿Qué ha ocurrido con los imaginarios acerca de las instituciones políticas?

P.G: Si la política no es capaz de crear una oferta de sentido que acompañe y explique las enormes transformaciones estructurales en las que estamos metidos y que descalabran la vida cotidiana, entonces surgirá un desamparo que la gente intentará compensar cediendo a las ofertas populistas e incluso autoritarias. Por ahora lo que se puede decir a la luz de los datos, y no de los nuestros, que aún no están listos, sino de cualquiera de los publicados por los centros de estudio, es que el imaginario prevalente sobre la política es que ella está cerrada sobre sí misma y que no puede esperarse de ella una oferta de sentido dirigida hacia la sociedad y hacia la vida cotidiana. La política no es vista como una aliada. El informe contendrá una invitación a la transformación de la cultura política actual. Entre otras cosas a transformar una cultura política que parece no haberse enterado de los cambios culturales. Pero también nos interesa la política en otro sentido, como producción simbólica de la polis. Esta vez, quisieramos centrar ahí nuestra creatividad teórica. Quisiéramos pensar la democracia como un trabajo cultural de la sociedad.

Pregunta: ¿Cuál es en realidad el carácter científico de los informes?

P.G.: Bien vistos los informes de desarrollo humano no dicen cosas demasiado originales, ni son instrumentos científicos infalibles. Lo que hacen es catalizar conversaciones sociales que aún no tienen lenguaje. La inseguridad y el malestar en Chile a fines del 97', por ejemplo, no 
tenían lenguaje, eran una sensación difusa. Los informes de desarrollo humano se prestan para favorecer una conversación social sobre algo que es ineludible pero que aún no ha llegado a formularse y eso determina la forma de nuestra producción científica. No queremos producir ciencia en un sentido puramente académico, no queremos probar hipótesis. Queremos producir argumentos sensatos y empíricamente plausibles que sean capaces de activar necesidades pendiente de debate público. En nuestro caso la ciencia está al servicio de aumentar la capacidad de debate, de la sociedad. Por lo mismo, nosotros no hacemos demasiada teoría en los informes. Por ejemplo, todo lo que nosotros hemos discutido ahora y que podríamos haberlo profundizado mucho más aún, no está en los informes. El informe tiene una función de catalizador y eso marca el tipo de método y la forma en que usamos los métodos y el modo cómo exponemos sus resultados. 